\title{
Pengendalian Kualitas Produk Tekstil Menggunakan Metoda DMAIC
}

\author{
Feby Ayu Lestari' ${ }^{1}$ Nining Purwatmini ${ }^{2}$ \\ ${ }^{1}$ Mahasiswa Universitas Bina Insani \\ ${ }^{2}$ Dosen Universitas Bina Insani, niningpurwatmini@binainsani.ac.id
}

\begin{abstract}
This study aims to observe the effectiveness of the application of the DMAIC method (Define, Measure, Analyze, Improve and Control) as a quality control model in the textile distribution business. DMAIC is part of quality control using six-sigma. In general, DMAIC is used by manufacturers to control quality. Quality is an important element, both for the product and for the process. Quality standards are set according to consumer desires. Therefore, it is necessary to control the quality carried out by the company. The purpose of quality control of finished goods is to ensure that the quality that the company will design and use is in line with the desires of the consumer. The research was conducted at PT Tekstil Distribution using quantitative descriptive data analysis techniques, based on observations and interviews. The method used in quality control research is the DMAIC method with a control device in the form of seven tools for total quality control, however not all of the tools from the seven tools in total quality control are used in the DMAIC method. The control tools used are only brainstorming, SIPOC (supply, input) diagrams, check sheets, and Pareto diagrams. The tools are used by PT. Tekstil Distribution as the tools used by PT Tekstil Distribution's QC (Quality Control) team in interpreting QC data for a certain period.
\end{abstract}

Keywords: Six Sigma Quality Control, DMAIC Method.

\begin{abstract}
ABSTRAK
Penelitian ini bertujuan mengamati efektivitas penerapan metode DMAIC (Define, Measure, Analyze, Improve dan Control) sebagai model pengendalian kualitas pada bisnis distribusi tekstil. DMAIC merupakan bagian dari pengendalian kualitas menggunakan six-sigma. Pada umumnya metode DMAIC digunakan oleh para produsen barang untuk mengendalikan kualitas. Kualitas merupakan elemen penting, baik bagi produk maupun bagi proses. Penetapan standar kualitas disesuaikan dengan keinginan konsumen. Oleh sebab itu, dibutuhkan pengendalian terhadap kualitas yang dilakukan oleh perusahaan. Tujuan dari pengendalian kualitas pada bisnis distribusi tekstil adalah pengendalian kualitas barang jadi, guna memastikan kualitas yang akan dirancang dan digunakan oleh perusahaan selaras dengan keinginan konsumen. Penelitian dilakukan di PT Distribusi Tekstil menggunakan teknik analisis data secara kualititatif, berdasarkan hasil observasi dan wawancara. Metode yang digunakan dalam penelitian pengendalian kualitas adalah metode DMAIC dengan alat kendali berupa seven tools pada total quality control, namun tidak semua alat kendali (tools) dari seven tools pada total quality control digunakan dalam metode DMAIC. Alat kendali yang digunakan hanya brainstorming, SIPOC (supply, input) diagram, check sheet, serta Pareto diagram. Alat-alat digunakan oleh PT Distribusi Tekstil sebagai alatalat yang digunakan oleh tim QC (Quality Control) PT Distribusi Tekstil dalam menginterpretasikan data QC pada suatu periode tertentu.
\end{abstract}

Kata Kunci: Pengendalian Kualitas Six Sigma, Metode DMAIC.

Accepted: 05-01-2021, Revision:29-12-2020, Published: 01-04-2021

\section{PENDAHULUAN}

Kualitas produk merupakan faktor penting demi menjaga kelangsungan hidup perusahaan, fakta dalam bisnis menyatakan bahwa permintaan konsumen terhadap mutu produk disertai meningkatnya jumlah produk dan jasa karena daya saing dan daya tahan setiap usaha tidak lagi ditentukan oleh rendahnya biaya tetapi dengan nilai tambah produk melalui peningkatan kualitas (Heizer, J., Render, B., \& Munson, 2014).

Pengendalian terhadap kualitas dinilai penting karena menjadi salah satu upaya untuk memenangkan persaingan usaha. Menurut, pengendalian kualitas apabila dilakukan dengan baik maka dibutuhkan biaya pengawasan kualitas, jika tidak dilakukan dengan baik maka 
menimbulkan kesulitan untuk memasarkan produk karena tersaingi dengan produk sejenis dengan kualitas lebih baik, sementara produk yang tidak disukai adalah karena jumlah produk cacat yang dimiliki perusahaan lebih banyak.

Metode Six Sigma merupakan salah satu cara untuk melakukan pengendalian proses industri yang berfokus pada konsumen dengan memperhatikan kemampuan dalam suatu proses. Six Sigma merupakan salah satu metode sebagai alternatif dalam prinsip-prinsip pengendalian kualitas yang merupakan terobosan di bidang manajemen kualitas. Metode yang digunakan dalam Six Sigma salah satunya adalah melalui tahapan DMAIC (Define, Measure, Analysis, Improve, Control). Metode DMAIC banyak diterapkan pada perusahaan kecil sampai menengah (C.R \& Thakkar, 2019) dan (Gupta et al., 2018).

\section{KAJIAN LITERATUR}

Tujuan Pengendalian Kualitas, menurut (Ahmed, 2019) pengendalian kualitas bertujuan untuk menjamin bahwa proses dilakukan dengan cara yang sesuai dengan standar yang ditetapkan kemudian menghasilkan produk atau jasa yang memenuhi kualitas yang diinginkan. Sedangkan menurut (Heizer, J., Render, B., \& Munson, 2014) tujuan pengendalian kualitas adalah agar produk akhir mempunyai spesifikasi sesuai dengan standar mutu atau kualitas yang telah ditetapkan, selain itu agar biaya desain produk, biaya inspeksi, dan biaya proses produksi dapat berjalan secara efisien. Prinsip pengendalian kualitas merupakan upaya untuk mencapai dan meningkatkan proses produksi, dengan cara melakukan inspeksi secara secara terus-menerus. Data dari inspeksi digunakan sebagai dasar untuk menganalisis agar menghasilkan informasi yang dapat digunakan untuk mengendalikan dan meningkatkan kualitas proses dan kualitas produk. Sehingga pada gilirannya proses produksi memiliki kemampuan untuk memenuhi spesifikasi produk yang diinginkan oleh pelanggan.

\section{Tahapan Pengendalian Kualitas Menggunakan Metoda DMAIC.}

DMAIC (Define, Measurement, Analyze, Improve and Control) adalah sebuah komponen dasar dari metodologi Six Sigma, yang digunakan untuk meningkatkan kinerja suatu proses dalam mengidentifikasi cacat atau defect. Siklus DMAIC yang dikembangkan oleh Edward Deming seperti disampaikan pada gambar 1, dan berguna untuk memperbaiki sebuah proses bisnis untuk mengurangi cacat produksi.

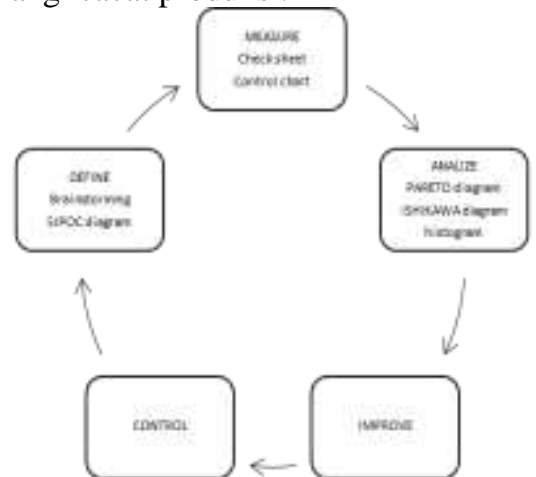

Sumber: (Heizer and Render, 2016)

Gambar 1. siklus DMAIC pada six sigma

Adapun tahapan pada metode DMAIC menurut (Srinivasan et al., 2016) dan (Heizer, J., Render, B., \& Munson, 2014) sebagai berikut:

1. Define, merupakan langkah awal di dalam metode Six Sigma. Define adalah mengidentifikasi karakteristik kualitas kunci yang berhubungan langsung dengan kebutuhan spesifik dari pelanggan dan menentukan tujuan. Hasil yang akan diperoleh dari tahap define terdiri atas: pernyataan yang jelas mengenai improvement yang akan dilakukan, serta peta proses (process map) berupa sebuah diagram aliran kerja yang dipakai untuk memahami proses produksi barang maupun jasa dengan lebih baik. Tujuan dari sisi produsen dalam pembuatan peta proses adalah untuk memperbaiki atau meningkatkan produktivitas proses dan menghilangkan pemborosan.

Berikut adalah tools yang dipakai dalam proses define:

a. Brainstorming, merupakan alat yang dapat digunakan untuk menghasilkan ide dan juga bertujuan untuk mendapatkan gagasan baru dari anggota tim dalam waktu yang relatif singkat tanpa adanya sifat kritis yang ketat (Lenka Girmanová et al., 2017) .

b. Diagram SIPOC (Supplier, Input, Process, Output dan Customer), menurut diagram ini merupakan salah satu tehnik yang menampilkan aliran kerja secara luas dan sering digunakan untuk proses perbaikan kualitas. Diagram SIPOC digunakan sebagai alat identifikasi elemen-elemen yang berkaitan dalam suatu proses produksi, antara lain siapa pemasoknya, apa inputnya, bagaimana prosesnya, apa hasilnya dan siapa saja pemakainya (Febria Suci et al., 2017). 
2. Measure, tahap ini berupa tahap pengukuran yang dilakukan melalui pengambilan sampel yang dilakukan oleh perusahaan pada periode waktu tertentu. Tools yang dipakai pada tahap Measure terdiri atas (Sharma et al., 2018b):

a. Check Sheet, yaitu formulir pengumpulan data khusus yang hasilnya dapat diinterpretasikan pada formulir tersebut secara langsung tanpa membutuhkan pemrosesan lebih lanjut.

b. Control Chart atau peta kendali, berupa grafik yang digunakan untuk mengkaji perubahan proses dari waktu ke waktu. Control Chart adalah salah satu alat yang berbentuk grafik dan dipergunakan untuk memantau stabilitas dari suatu proses serta memperlajari perubahan proses dari waktu ke waktu. Chart ini memiliki garis atas (Upper Line) untuk Batas kontrol tertinggi (Upper Control Limit) dan garis bawah (Lower Line) untuk Batas kontrol terendah (Lower Control Limit) dan garis tengah (Central Line) untuk rata-rata (Average).

3. Analyze, merupakan tahap identifikasi penyebab masalah terkait kualitas dengan menggunakan alat sebagai berikut (Sharma et al., 2018a):

a. Diagram Pareto, menurut, diagram pareto adalah metode dalam mengorganisasikan kesalahan, atau cacat untuk membantu fokus atas usaha penyelesaian masalah. Diagram pareto digunakan untuk membandingkan berbagai kategori kejadian yang disusun menurut ukurannya dari yang paling besar disebelah kiri yang paling kecil di sebelah kanan. Dengan bantuan diagram pareto, kegiatan akan lebih efektif dengan memusatkan perhatian pada sebab-sebab yang mempunyai dampak paling besar terhadap kejadian daripada meninjau berbagai sebab pada suatu ketika.

b. Histogram, Histogram merupakan diagram batang yang miring atau tidak simetris yang menunjukkan bahwa banyak data yang tidak berada pada nilai rata-ratanya tetapi kebanyakan datanya berada pada batas atas atau bawah.

c. Diagram Ishikawa (Cause and Effect Diagram), diagram sebab akibat merupakan diagram yang menggambarkan hubungan timbal balik antara masalah dengan faktor yang menyebabkannya
4. Improve, merupakan fase yang berguna untuk mengembangkan ide dan menerapkan perbaikan serta validasi perbaikan. Dalam fase ini ada 3 hal pokok yang harus dikerjakan yaitu (Yurin Febria Suci, Yuki Novia Nasution, 2017):

a. Mengetahui penyebab potensial yang menyebabkan variasi proses.

b. Menemukan hubungan variabel-variabel kunci penyebab variasi.

c. Menetapkan batas-batas toleransi operasional.

5. Control, merupakan fase terakhir peningkatan kualitas menggunakan metode DMAIC. Dalam fase ini, dilakukan pengaturan proses atau perbaikan produk serta pemantauan kinerja yang sedang berjalan. Selain itu, fase control juga memastikan bahwa perbaikan yang baru dapat dilakukan. Pada tahap ini hasil-hasil peningkatan kualitas didokumentasikan dan disebarluaskan serta dijadikan pedoman kerja standar, kepemilikan dan penanggung jawab proses meyatakan bahwa pengendalian kualitas berbasis six sigma bukanlah suatu cara pengendalian kualitas yang rumit dan berteknologi tinggi. Cara sederhana dan mudah serta memberikan ruang bagi perbaikan bersinambung (continuous inprovement) melalui penerapan metode DMAIC. Metode memungkinkan perusahaan untuk mengendalikan kualitas produk dan proses bersamaan, sehingga meningkatkan kinerja unit produksi.

Penelitian lain yang dilakukan oleh Yadav dan Sukhwani (2016) menghasilkan kesimpulan bahwa penerapan six sigma menggunakan metode DMAIC pada pabrik otomotif di India dapat mengurangi penolakan terhadap produk (DPMO = defect per million output) 68.181 menjadi 9.090,9. Hal ini dimungkinkan karena DMAIC menggunakan metoda analisa secara statistik.

Pengendalian kualitas pada sebuah pabrik roti durian juga dapat dilakukan menggunakan penerapan metode DMAIC dari six sigma, seperti yanmg dilakukan oleh Suci, Nasution \& Rizky (2017). Mereka menyimpulkan bahwa metoda DMAIC dapat melakukan penelusuran terhadap penyebab terjadinya cacat produk. Penyebab tersebut meliputi faktor manusia/ pekerja, bahan baku, lingkungan, mesin serta metode kerja.

Chakrabortty, Biswas dan Ahmed menyatakan dalam penelitiannya bahwa penerapan metode DMAIC akan memperkecil variabilitas proses pada industri makanan di Bangladesh. Metode ini memungkinkan untuk mentelusuri akar 
peramasalahan yang menyebabkan timbulnya variabilitas proses.

\section{METODE PENELITIAN}

Penelitian dilakukan menggunakan berupa uji fisik atas contoh produk (sample) terutama utntuk produk berwarna selain hitam, dilakukan uji fisik atas sejumlah $30 \%$ random sample dari total produk dalam batch. Untuk produk dengan warna hitam pekat dilakukan QC $100 \%$ check, yaitu keseluruhan fisik kain dilakukan QC tanpa terkecuali. Metode penelitian yang digunakan adalah metode kualitatif berdasarkan observasi yaitu pengamatan terhadap sample kemudian membandingkan dengan standar warna yang ditetapkan. Tahapan pengamatan menggunakan metode DMAIC. Dilakukan rekapitulasi menggunakan diagram Pareto terhadap data defect (hasil pengamatan tidak sesuai dengan standar yang ditetapkan) dari hasil pengamatan menggunakan metode DMAIC. (IW Suwendra, 2018) dan (A Manzilati, 2017).

\section{PEMBAHASAN}

PT Distribusi Tekstil adalah perusahaan yang bergerak dibidang textile marketing \& distributor untuk tekstil jenis polyester $100 \%$. Perusahaan bekerja sama dengan beberapa pabrik tekstil sebagai pemasok tekstil tanpa merek. Perusahaan memberikan textile brand dengan nama "Textileone", disesuaikan dengan spesifikasi dan standar yang sudah ditentukan (L Girmanová et al., n.d.). Proses Quality Control dilakukan setelah proses penginputan barang selesai. Pengecekan dilakukan berdasarkan kategori brand yang dimiliki oleh perusahaan.

\section{Tahapan Pemeriksaan}

Agar tercapai kualitas barang yang diinginkan konsumen, bagian Quality Control product test berupa evaluasi produk yang baru datang. Pengecekan ini dimaksudkan untuk mengetahui kesesuaian hasil pengecekan dengan indikator standar (Heizer, J., Render, B., \& Munson, 2014).

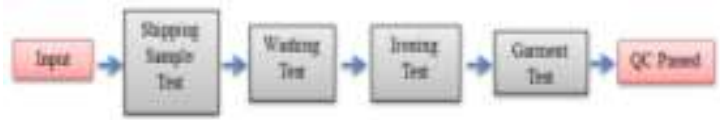

Sumber: Penelitian (2019)

Gambar 1. Alur Tahapan Product Test

Gambar 2 adalah diagram alur tahapan product test pada tekstil sebelum didistribusikan kepada konsumen. Input, textile diproduksi oleh beberapa pemasok dan dikirimkan ke gudang PT Distribusi Tekstil. Kemudian dilakukan pengecekan berdasarkan daftar packing list, kemudian dijadikan dasar untuk pengecekan kualitas tahap berikutnya. Shipping Sample Test, tahapan pertama dalam proses QC, terdapat enam titik yang harus diperhatikan dalam tahapan ini. Titik-tersebut meliputi random check, yaitu Pengecekan terhadap warna Kemudian dilakukan visual check untuk melihat kesetaraan warna pada sampel yang diambil. Toleransi maksimal yang diberikan adalah $0,8 \%$, jika memenuhi maka diberi cap "OK". Jika terdapat penyimpangan pada sampel maka dikembalikan, ke pabrik, lalu dilakukan produksi ulang. Guna menentukan aspek penentu kualitas yang menunjukkan penyimpangan terbesar, PT Distribusi Tekstil menggunakan diagram Pareto pada divisi QC, guna mempermudah melihat dan menganalisa masalah terkait kontributor terbesar pada penyimpangan kualitas. Data guna penyusunan diagram pareto untuk periode waktu selama 2 sampai 6 bulan.

Berikut adalah diagram pareto yang dibuat oleh divisi QC PT Distribusi Tekstil.

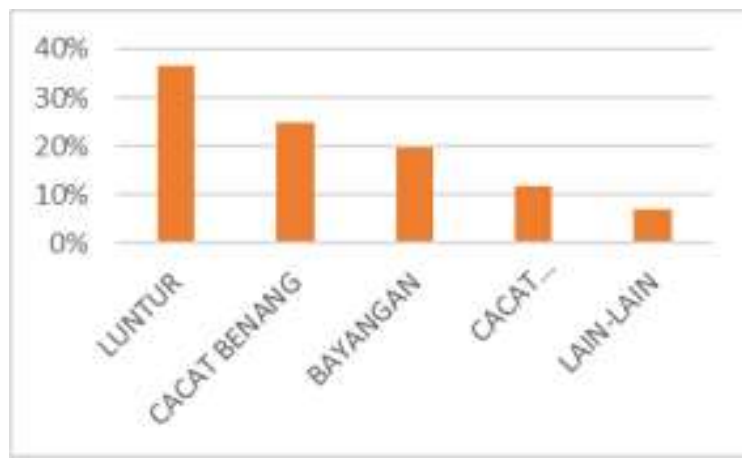

Sumber: Penelitian (2019)

Gambar 3. Diagram Pareto diolah berdasarkan Data Cacat (2018)

Diagram Pareto diolah pada gambar 3, menunjukkan bahwa kontributor tebesar penyimpangan kualitas atau cacat adalah "fastness/ tingkat kelunturan" sebesar 36\% namun setelah dilakukan pengendalian kualitas menggunakan DMAIC, defect luntur turun menjadi $22 \%$. Mengacu pada hasil analisa menggunakan Pareto, maka dilakukanlah pengendalian kualitas menggunakan DMAIC terhadap tingkat kelunturan. Pengendalian tingkat kelunturan dilakukan dengan "uji pencucian". Uji pencucian terdiri dari dua macam, yaitu pencucuian dengan tangan dan pencucian dengan mesin.

Metode DMAIC yang digunakan guna mengendalikan kualitas tekstil meliputi lima tahap. Pada tahap $D$ (define) bahwa brainstorming dan diagram SIPOC digunakan oleh PT Distribusi Tekstil karena berfokus pada pengembangan 
barang jadi sesuai dengan keinginan customer. Tahap $M$ (measure) menerapkan check sheet sebagai alat rekap data pada setiap kedatangan barang yang berasal dari pemasok. Sedangkan control chart tidak digunakan oleh PT Distribusi Tekstil karena tidak sesuai dengan kondisi divisi QC di perusahaan. Tahap A (analyze) menggunakan diagram Pareto sebagai interpretasi visual data dalam bentuk grafik, sehingga dengan mudah terlihat jumlah defect berdasarkan jenis defect yang kemungkinan terjadi. Pada tahap ini, histogram tidak digunakan oleh PT Distribusi Tekstil, karena diagram Pareto dinilai lebih mudah diterapkan. Diagram sebab akibat digunakan oleh PT Distribusi Tekstil dalam identifikasi akar penyebab dari suatu masalah yang memiliki keterkaitan dalam proses.

Dalam pembuatan diagram ini, seringkali ditemukan human error yang terdapat pada elemen people. Hasil dari diagram sebab akibat menjadi sebuah acuan dalam melakukan perubahan secara lebih detail dari berbagai sisi. Pada tahap improve dilakukan pengembangan terhadap suatu proses yang sebelumnya telah diterapkan tetapi belum mendapatkan hasil yang maksimal. Tahap I (improve) pada PT Distribusi Tekstil diterapkan langsung oleh pihak pemasok, dan peran divisi QC hanyalah sebatas pemberi referensi dan saran sesuai dengan standarisasi kualitas yang ingin dicapai oleh perusahaan. Pada tahap $C$ (control) yang dilakukan oleh PT Distribusi Tekstil adalah melakukan pengawasan terhadap kualitas yang dihasilkan dari rangkaian proses yang telah dijalankan.

Tabel 1. Skala Perubahan Warna

\begin{tabular}{cc}
\hline $\begin{array}{c}\text { Range Nilai } \\
\text { Tahan Luntur } \\
\text { Warna }\end{array}$ & $\begin{array}{c}\text { Evaluasi Tahan Luntur } \\
\text { Warna }\end{array}$ \\
\hline $\mathbf{4 - 5}$ & Baik Sekali \\
\hline $\mathbf{3 - 4}$ & Baik \\
\hline $\mathbf{2}-\mathbf{3}$ & Cukup \\
\hline $\mathbf{1}-\mathbf{2}$ & Buruk
\end{tabular}

Sumber: penelitian (2019)
Tabel 2. Proses Pengamatan metode DMAIC untuk proses hand washing (cuci manual)

\begin{tabular}{|c|c|c|c|}
\hline Metode & $\begin{array}{c}\text { Non } \\
\text { Detergent }\end{array}$ & $\begin{array}{c}\text { Detergent } \\
\text { Low } \\
\text { Concentrat } \\
e\end{array}$ & $\begin{array}{c}\text { Detergent } \\
\text { Med } \\
\text { Concentrat } \\
e\end{array}$ \\
\hline Define & $\begin{array}{l}\text { No } \\
\text { Discolor. }\end{array}$ & $\begin{array}{l}\text { No } \\
\text { Discolor }\end{array}$ & $\begin{array}{l}\text { No } \\
\text { Discolor }\end{array}$ \\
\hline Measure & $\begin{array}{l}5 \quad \text { (skala } \\
\text { kelunturan } \\
\text { sangat } \\
\text { sedikit } \\
\text { dalam batas } \\
\text { toleransi } \\
\text { OK); }\end{array}$ & $\begin{array}{l}4-5 \text { (skala } \\
\text { kelunturan } \\
\text { sedikit } \\
\text { dalam batas } \\
\text { toleransi } \\
\text { OK); }\end{array}$ & $\begin{array}{l}4-5 \text { (skala } \\
\text { kelunturan } \\
\text { sedikit } \\
\text { dalam batas } \\
\text { toleransi } \\
\text { OK). }\end{array}$ \\
\hline Analyze & $\begin{array}{l}\text { Chemical } \\
\text { color yang } \\
\text { digunakan } \\
\text { oleh pabrik } \\
\text { berbeda- } \\
\text { beda dan } \\
\text { temperatur } \\
\text { yang belum } \\
\text { tepat. }\end{array}$ & $\begin{array}{l}\text { Chemical } \\
\text { color yang } \\
\text { digunakan } \\
\text { oleh pabrik } \\
\text { berbeda- } \\
\text { beda dan } \\
\text { temperatur } \\
\text { yang belum } \\
\text { tepat. }\end{array}$ & $\begin{array}{l}\text { Chemical } \\
\text { color yang } \\
\text { digunakan } \\
\text { oleh pabrik } \\
\text { berbeda- } \\
\text { beda dan } \\
\text { temperatur } \\
\text { yang belum } \\
\text { tepat. }\end{array}$ \\
\hline Improve & $\begin{array}{l}\text { OK. Can } \\
\text { shipping to } \\
\text { customer. }\end{array}$ & $\begin{array}{l}\text { OK. Can } \\
\text { shipping to } \\
\text { customer. }\end{array}$ & $\begin{array}{l}\text { OK. Can } \\
\text { shipping to } \\
\text { customer. }\end{array}$ \\
\hline Control & Dilakukan & Dilakukan & Dilakukan \\
\hline & $\begin{array}{l}\text { uji test } \\
\text { secara } \\
\text { berkala. }\end{array}$ & $\begin{array}{l}\text { uji test } \\
\text { secara } \\
\text { berkala. }\end{array}$ & $\begin{array}{ll}\text { uji } & \text { test } \\
\text { secara } & \\
\text { berkala. }\end{array}$ \\
\hline
\end{tabular}

Sumber: Penelitian (2019)

Tes Cuci (Washing Test), tes cuci bertujuan untuk mengetahui perubahan penampakan warna kain, serta mengetahui tingkat kelunturan warna (color fastness) khusus untuk warna-warna tua, unsur merah dan hitam pekat (jet black series). Pada test cuci ini perusahaan menerapkan metode DMAIC dari six sigma.test menjadi hal yang sangat penting bagi indutri tekstil, mengingat kualitas utama produk tekstil adalah kemampuan mempertahan warna dalam jangka waktu lama (setelah proses pencucian berkali-kali). Test cuci terdiri atas test cuci menggunakan tangan (hand washing), dan test cuci menggunakan mesin (machine washing).

Hasil test untuk hand washing

Selain hand washing, uji kelunturan juga dilakukan terhadap tekstil, menggunakan mesin cuci (machine wshing). Pengamatan terhadap machine washing, menggunakan metoda DMAIC, tertuang dalam tabel 4 berikut. Efektifitas pengendalian kualitas yang telah diterapkan oleh PT Distribusi Tekstil memiliki tujuan, agar barang yang dihasilkan sesuai dengan standar yang telah ditetapkan oleh PT Distribusi Tekstil serta memenuhi keinginan customer. 
Tabel 3. Proses Pengamatan metode DMAIC untuk proses machine washing (cuci mesin)

\begin{tabular}{|c|c|c|c|}
\hline Metode & $\begin{array}{c}\text { Non } \\
\text { Detergent }\end{array}$ & $\begin{array}{c}\text { Detergent } \\
\text { Low } \\
\text { Concentrate }\end{array}$ & $\begin{array}{c}\text { Detergent } \\
\text { Med } \\
\text { Concentrate }\end{array}$ \\
\hline Define & No Discolor. & No Discolor & No Discolor \\
\hline $\begin{array}{l}\text { Measur } \\
e\end{array}$ & $\begin{array}{l}4 \quad \text { dan } 5 \\
\text { (skala } \\
\text { kelunturan } \\
\text { sangat } \\
\text { sedikit dalam } \\
\text { batas } \\
\text { toleransi } \\
\text { OK); }\end{array}$ & $\begin{array}{l}4 \text { sampai } 5 \\
\text { (skala } \\
\text { kelunturan } \\
\text { sedikit dalam } \\
\text { batas } \\
\text { toleransi } \\
\text { OK); }\end{array}$ & $\begin{array}{l}4 \text { sampai } 5 \\
\text { (skala } \\
\text { kelunturan } \\
\text { sedikit dalam } \\
\text { batas } \\
\text { toleransi } \\
\text { OK). }\end{array}$ \\
\hline Analyze & $\begin{array}{l}\text { Chemical } \\
\text { color yang } \\
\text { digunakan } \\
\text { oleh pabrik } \\
\text { berbeda- } \\
\text { beda dan } \\
\text { temperatur } \\
\text { yang belum } \\
\text { tepat. }\end{array}$ & $\begin{array}{l}\text { Chemical } \\
\text { color yang } \\
\text { digunakan } \\
\text { oleh pabrik } \\
\text { berbeda- } \\
\text { beda dan } \\
\text { temperatur } \\
\text { yang belum } \\
\text { tepat. }\end{array}$ & $\begin{array}{l}\text { Chemical } \\
\text { color yang } \\
\text { digunakan } \\
\text { oleh pabrik } \\
\text { berbeda- } \\
\text { beda dan } \\
\text { temperatur } \\
\text { yang belum } \\
\text { tepat. }\end{array}$ \\
\hline Improve & $\begin{array}{lr}\text { OK. Can } \\
\text { shipping to } \\
\text { customer. }\end{array}$ & $\begin{array}{lr}\text { OK. Can } \\
\text { shipping to } \\
\text { customer. }\end{array}$ & $\begin{array}{lr}\text { OK. Can } \\
\text { shipping to } \\
\text { customer. }\end{array}$ \\
\hline Control & $\begin{array}{l}\text { Dilakukan } \\
\text { uji test } \\
\text { secara } \\
\text { berkala. }\end{array}$ & $\begin{array}{l}\text { Dilakukan } \\
\text { uji test } \\
\text { secara } \\
\text { berkala. }\end{array}$ & $\begin{array}{l}\text { Dilakukan } \\
\text { uji test } \\
\text { secara } \\
\text { berkala. }\end{array}$ \\
\hline
\end{tabular}

Rekapitulasi hasil uji kualitas menggunakan metode DMAIC terhadap tingkat kelunturan, ditunjukkan pada gambar 4 berikut:

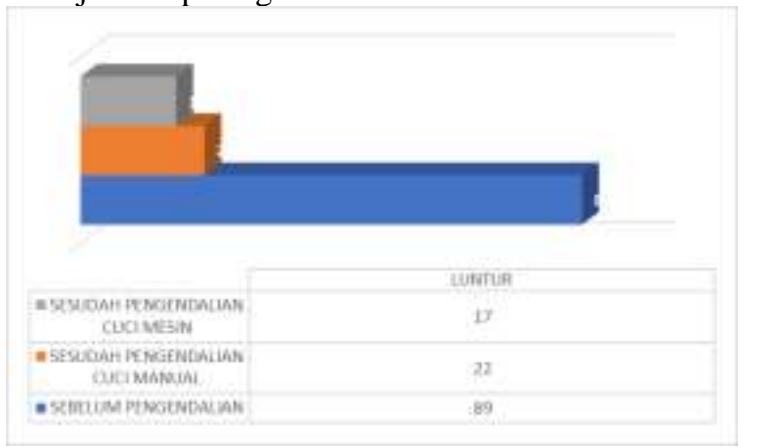

Sumber: Penelitian (2019)

Gambar 4. Diagram diolah berdasarkan Data

Luntur sebelum dan sesudah pengendalian (2018)

\section{SIMPULAN}

Simpulan yang didapat dari hasil penelitian pada divisi Quality Control (QC) di PT Distribusi Tekstil, bahwa divisi QC PT Distribusi Tekstil melakukan pengendalian kualitas menggunakan metode DMAIC. Pengendalian kualitas pada penelitian kali ini terbatas pada jenis tekstil yang masuk ke gudang pada periode pengambilan sample. Belum mencakup lebih banyak jenis tekstil lannya. Sehingga efektivitas penggunaan metode DMAIC masih terbatas pada tekstil Penerapan (implikasi) metode DMAIC pada pengendalian kualitas produk tekstil cukup efektif. Efektifitas ini ditunjukkan dari hasil pengendalian kualitas telah menurunkan tingkat luntur, dari 89 sample menjadi 39 sample. Jumlah 39 sample yang menunjukkan luntur tersebut, didapat dari uji kualitas menggunakan cuci manual sebanyak 22 sample, sedangkan uji kualitas menggunakan mesin menunjukkan tingkat luntur sebanyak 17 sample. Uji kualitas menngunakan metode DMAIC ini dilaksanakan sesuai dengan alur meliputi input, shipping sample test, washing test, ironing test, garment test dan QC passed.

Pemilihan pengendalian kualitas menggunakan metode DMAIC merupakan pemilihan yang tepat, karena tahapan yang dilakukan dalam metode DMAIC dapat menelusuri jenis dan tingkat penyimpangan yang terjadi. Penelusuran tersebut seperti ditunjukkan dari hasil peneltian pada tabel 2 dan tabel 3. Disarankan kepada para peneliti selanjutnya, agar memilih produk tekstil jenis lain, yang belum termasuk dalam sample tekstil yang telah diteliti dengan perlakuan menggunakan berbagai jenis bahan cuci deterjen. Saran ini damkudkan agar efektivitas metode DMAIC teruji sebagai metode pengendalan kualitas produk tekstil.

\section{REFERENSI}

A Manzilati. (2017). Metodologi Penelitian Kualitatif: Paradigma, Metode, dan Aplikasi.

Ahmed, S. (2019). Integrating DMAIC approach of Lean Six Sigma and theory of constraints toward quality improvement in healthcare. Rev Environ Health, 34(4), 427-434. https://doi.org/10.1515/reveh-2019-0003

C.R, A., \& Thakkar, J. J. (2019). Application of Six Sigma DMAIC methodology to reduce the defects in a telecommunication cabinet door manufacturing process: A case study. International Journal of Quality and Reliability Management, 36(9). https://doi.org/10.1108/IJQRM-12-20180344

Febria Suci, Y., Novia Nasution, Y., Nanda, D., \& Rizki, A. (2017). Program Studi Statistika FMIPA Universitas Mulawarman 27 Penggunaan Metode Seven New Quality 
Tools dan Metode DMAIC Six Sigma Pada Penerapan Pengendalian Kualitas Produk (Studi Kasus: Roti Durian Panglima Produksi PT. Panglima Roqiiqu Group Samarinda) Used of Seven New Quality Tools Method and DMAIC Six Sigma Method on Applied Product Quality Control (Case Study of Roti Durian Panglima Produced by PT. Panglima Roqiiqu Group Samarinda). Jurnal EKSPONENSIAL, 8(1). https://jurnal.umj.ac.id/index.php/jisi/article/ view/4061

Girmanová, L, Šolc, M., ... J. K.-A. technologica, \& 2017, undefined. (n.d.). Application of Six Sigma using DMAIC methodology in the process of product quality control in metallurgical operation. Content.Sciendo.Com. https://doi.org/10.1515/ata-2017-0020

Girmanová, Lenka, Šolc, M., Kliment, J., Divoková, A., \& Mikloš, V. (2017). Application of Six Sigma Using DMAIC Methodology in the Process of Product Quality Control in Metallurgical Operation. Acta Technologica Agriculturae, 20(4). https://doi.org/10.1515/ata-2017-0020

Gupta, V., Jain, R., Meena, M. L., \& Dangayach, G. S. (2018). Six-sigma application in tiremanufacturing company: a case study. Journal of Industrial Engineering International, $\quad$ 14(3). https://doi.org/10.1007/s40092-017-0234-6

Heizer, J., Render, B., \& Munson, C. (2014). (11. utg. ). E. P. (2014). Operations Management-Sustainability and supply chain management.

IW Suwendra. (2018). Metodologi penelitian kualitatif dalam ilmu sosial, pendidikan, kebudayaan dan keagamaan.

Sharma, P., Malik, S. C., Gupta, A., \& Jha, P. C. (2018a). A DMAIC Six Sigma approach to quality improvement in the anodising stage of the amplifier production process. International Journal of Quality and Reliability Management, 35(9). https://doi.org/10.1108/IJQRM-08-20170155

Sharma, P., Malik, S. C., Gupta, A., \& Jha, P. C. (2018b). A DMAIC Six Sigma approach to quality improvement in the anodising stage of the amplifier production process. International Journal of Quality and
Reliability Management, 35(9), 1868-1880. https://doi.org/10.1108/IJQRM-08-20170155

Srinivasan, K., Muthu, S., Devadasan, S. R., \& Sugumaran, C. (2016). Article in Production Planning and Control. Taylor \& Francis, 27(10), 810-822. https://doi.org/10.1080/09537287.2016.1143 130

Yurin Febria Suci1, Yuki Novia Nasution2, dan N. A. R. (2017). Penggunaan Metode Seven New Quality Tools dan Metode DMAIC Six Sigma Pada Penerapan Pengendalian Kualitas Produk (Studi Kasus: Roti Durian Panglima Produksi PT. Panglima Roqiiqu Group Samarinda). 8, 27-36. 